\title{
Calcium binding protects E-cadherin from cleavage by Helicobacter pylori HtrA
}

Thomas P. Schmidt ${ }^{1}$, Camilla Goetz ${ }^{1}$, Markus Huemer ${ }^{1}$, Gisbert Schneider ${ }^{2}$ and Silja Wessler ${ }^{{ }^{*}}$

\begin{abstract}
Background: The cell adhesion and tumor suppressor protein E-cadherin is an important factor in the establishment and maintenance of epithelial integrity. E-cadherin is a single transmembrane protein, which consists of an intracellular domain (IC), a transmembrane domain (TD), and five extracellular domains (EC). EC domains form homophilic interactions in cis and trans that require calcium binding to the linker region between the EC domains. In our previous studies, we identified the serine protease high temperature requirement $\mathrm{A}(\mathrm{H} \operatorname{tr} \mathrm{A})$ from the human pathogen and class-I carcinogen Helicobacter pylori (H. pylori) as a bacterial E-cadherin-cleaving protease that targets the linker region of the EC domains, thereby disrupting gastric epithelial integrity. However, it remains unclear how calcium binding to the E-cadherin linker regions affects HtrA-mediated cleavage.

Results: Investigating the influence of calcium on the HtrA-mediated cleavage of recombinant E-cadherin ( $\mathrm{rCdh}$ 1) in vitro, we tested different concentrations of calcium ions and the calcium chelator ethylenediaminetetraacetic acid (EDTA). Calcium efficiently reduced HtrA-mediated E-cadherin fragmentation. Conversely, the addition of EDTA strongly increased cleavage, resulting in a ladder of defined E-cadherin fragments. However, calcium ions did not affect HtrA oligomerization and protease activity as monitored by degradation of the universal protease substrate casein. Finally, addition of ethyleneglycol-bis-tetraacetic acid (EGTA) slightly enhanced E-cadherin cleavage during $H$. pylori infection of gastric epithelial cells.
\end{abstract}

Conclusions: Our results suggest that calcium blocks HtrA-mediated cleavage by interfering with the accessibility of calcium-binding regions between the individual EC domains, which have been identified as cleavage sites of HtrA.

Keywords: Helicobacter pylori, HtrA, E-cadherin, Calcium, Protease

\section{Background}

The gastric mucosa provides important functions in the intake of nourishment and immunity, but also acts as an efficient barrier to mechanical and chemical influences as well as pathogenic microorganisms. The integrity of the protective epithelium is established by junctional complexes, including tight junctions, adherens junctions or desmosomes [1]. Epithelial cadherin (E-cadherin, Cdh1) is the key molecule of adherens junctions and is implicated in the establishment of intercellular adhesion and tumor suppression of human epithelia [2, 3]. Structurally, E-cadherin consists of an intracellular domain (IC),

\footnotetext{
*Correspondence: silja.wessler@sbg.ac.at

${ }^{1}$ Cancer Cluster Salzburg, Department of Molecular Biology, Division

of Microbiology, Paris-Lodron University, Salzburg, Austria

Full list of author information is available at the end of the article
}

a single transmembrane domain (TD), and an extracellular domain (EC). The extracellular domain of E-cadherin is composed of five extracellular tandem repeats (called EC1-EC5) (Fig. 1a). Metal-binding motifs that bind calcium ions are located between the individual EC domains, and these are required for homophilic interactions between the domains. Upon calcium binding, E-cadherin changes its three-dimensional structure from a flexible conformation to a rigid, rod-like assembly favoring trans-interactions of EC domains 1 and 3 . Further, calcium-binding has also been implicated in cis-oligomerization [4-11]. The intracellular domain of E-cadherin is bound by members of the catenin family, in particular $\beta$-catenin and catenin ${ }^{\mathrm{p} 120}$, which stabilizes E-cadherin-mediated intercellular adhesion. Through binding to E-cadherin, $\beta$-catenin bridges the IC domain 


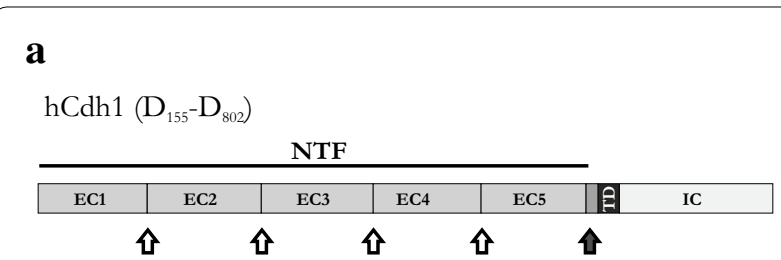

b

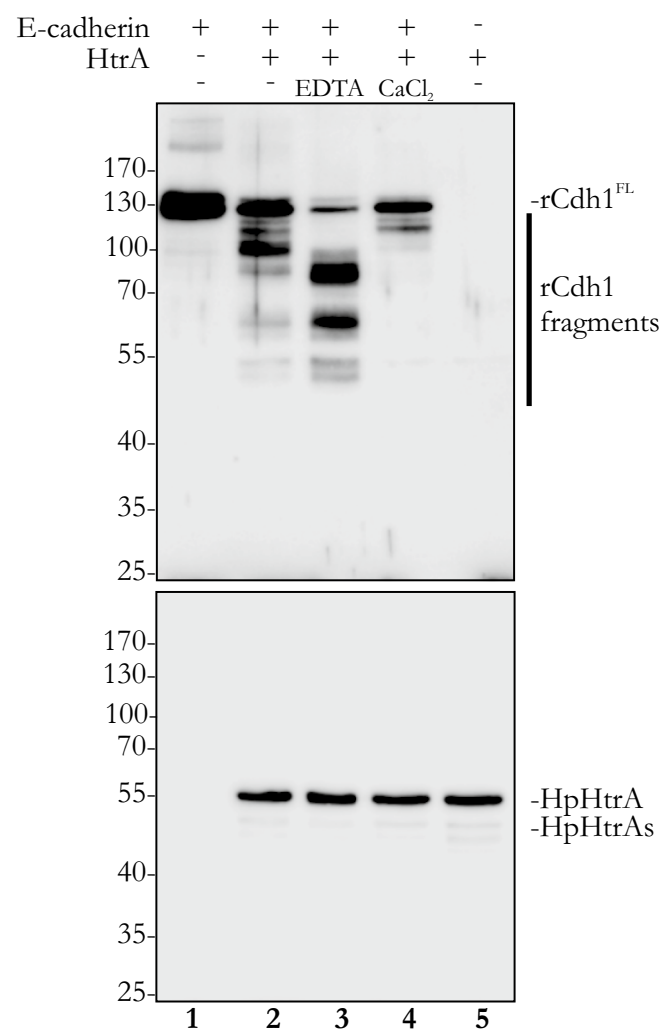

Fig. 1 Calcium ions change the HtrA-mediated E-cadherin cleavage pattern. a Model of the domain structure of human E-cadherin (hCdh1). EC extracellular domain, TD transmembrane domain, IC intracellular domain, NTF soluble N-terminal fragment, open arrows signature sites for $\mathrm{HtrA}$, black arrow cleavage site in the linker region. b $100 \mathrm{ng}$ rCdh1 was incubated with $200 \mathrm{ng} \mathrm{HpHtrA}$ and, where indicated, with $125 \mu \mathrm{M}$ EDTA or $100 \mu \mathrm{M} \mathrm{CaCl}$. Full-length E-cadherin $\left(\mathrm{rCdh} 1^{\mathrm{FL}}, \sim 125 \mathrm{kDa}\right)$ and $\mathrm{rCdh} 1$ fragments were detected by western blot using an antibody against the EC5 domain of E-cadherin. HpHtrA and the auto-processed short $\mathrm{HpH} \mathrm{HrA}(\mathrm{HpH} \mathrm{trAs})$ were probed using a polyclonal antibody to show equal loading

to the actin cytoskeleton via direct binding to $\alpha$-catenin or through interactions with additional factors, such as epithelial protein lost in neoplasm (EPLIN), myosin VI or vinculin [12-15]. Besides their important role in intercellular adhesion, intact E-cadherin-mediated adherens junctions function as significant tumor suppressors. Disruption of adherens junctions leads to a release of $\beta$-catenin and catenin ${ }^{\mathrm{p} 120}$ from the IC, which can then translocate into the nucleus where they interfere with the $\mathrm{T}$ cell factor/lymphoid enhancer factor (Tcf/Lef)-driven transactivation of cancer-associated genes (e.g. $c$-myc, cyclin d1) [16]. Importantly, there is a strong correlation between dysfunctional E-cadherin and cancer malignancy. Loss-of-function mutations, (epi) genetically downregulated $c d h 1$ expression or ectodomain cleavage influence the intercellular adhesion and the subcellular localization of associated catenins with severe consequences for cancer development and progression, particularly an increase in cellular invasiveness and metastasis [17].

E-cadherin also represents an attractive target for intruding human pathogens $[18,19]$. Infections with the gastric pathogen and class-I carcinogen Helicobacter pylori (H. pylori) have been described to induce the disintegration of the E-cadherin complex in gastric epithelial cell lines leading to severe alterations in epithelial polarity [20-22]. H. pylori infections are widespread: an estimated $50 \%$ of the world's population is infected [23]. Although eradication of $H$. pylori with antibiotics is possible, its close association with the induction of duodenal and gastric ulcers, gastritis, mucosa-associated lymphoid tissue (MALT) lymphoma, and gastric cancer makes it a pathogen with a considerable impact on the health of its human host [24-26]. In recent studies, the bacterial serine protease high temperature requirement A ( HtrA) was identified as a $H$. pylori-secreted factor that cleaves E-cadherin on gastric epithelial cells, thereby opening adherence junctions and disturbing the integrity of the gastric epithelial barrier [27]. HtrA proteases are chaperones and serine proteases that play important roles in protein quality control through their ability to refold and degrade misfolded proteins [28]. Members of the HtrA family of proteases have an N-terminal signal peptide, a protease domain and up to two PDZ (post synaptic density protein, Drosophila disc large tumor suppressor, zonula occludens-1 protein) domains. The PDZ domains regulate the protease function and oligomerization. For the $E$. coli homologue DegP, it has been shown that the hexamer presents the inactive state, whereas proteolytically active polyhedral cages (12, 24-mers) are formed for substrate degradation $[28,29]$. However, DegP cage assembly and proteolytic activation can be uncoupled [30]. E-cadherin cleavage by prokaryotic HtrA proteases has also been described for several other gastrointestinal pathogens, such as enteropathogenic Escherichia coli (EPEC), Shigella flexneri and Campylobacter jejuni [3134], leading to the presumption that E-cadherin cleavage might be a general pathogenicity mechanism for gastric pathogens.

Although the cleavage events of E-cadherin on polarized gastric epithelial cell lines have been intensively 
investigated, detailed information about the molecular mechanisms of HtrA-mediated E-cadherin cleavage is still scarce. In our previous work, we identified the calcium-binding motifs as signature sites in the E-cadherin molecule that are preferentially targeted by $H$. pylori HtrA (HpHtrA) [35]. Interestingly, these signature sites are differentially accessible for $\mathrm{HpHtrA}$, which might depend upon their homophilic interactions in cis and trans [35]. However, it remained completely unclear whether calcium binding affects HtrA activity and/or E-cadherin cleavage. Therefore, we have investigated the influence of calcium ions on the cleavage of E-cadherin by $\mathrm{HpHtrA}$ to provide a more detailed insight into the molecular mechanism through which $\mathrm{HpHtrA}$ interferes with E-cadherin functions.

\section{Results}

\section{Depletion of calcium ions enhances HtrA-mediated E-cadherin cleavage}

The bacterial protease HtrA secreted by $H$. pylori mediates efficient E-cadherin ectodomain (NTF, N-terminal fragment) shedding to open intercellular adhesion of polarized epithelial cells $[27,33]$. We previously identified the residue motif [VITA] $\downarrow[$ VITA]- $x-x-D-[D N]$ within the E-cadherin signature sites as preferred cleavage positions for HpHtrA [35]. These target sites are located between the individual EC domains (Fig. 1a, open arrows). Since these motifs are known to bind calcium ions $[3,5,8]$, which are crucially important for the adhesive properties of E-cadherin, we investigated whether calcium ions affect HtrA-mediated cleavage of E-cadherin. According to the manufacturer's instructions, recombinant E-cadherin (rCdh1) was reconstituted in phosphate-buffered saline (PBS), resulting in a final concentration of $45 \mu \mathrm{M}$ $\mathrm{CaCl}_{2}$ in the in vitro cleavage reaction. Recombinant Cdh1 was incubated with HpHtrA for $16 \mathrm{~h}$ in vitro, and then E-cadherin fragmentation was analyzed by western blot using an antibody recognizing EC5. Full-length rCdh1 has a molecular weight of approximately $125 \mathrm{kDa}$ (Fig. 1b, lane 1). Incubation with HpHtrA resulted in a partial cleavage. As previously described [35], a predominant $\sim 100 \mathrm{kDa}$ EC5-containing cleavage fragment and several minor products of $\sim 90 \mathrm{kDa}, \sim 60 \mathrm{kDa}$, and $\sim 50 \mathrm{kDa}$ were detected, while a large amount of full-length rCdh1 was still observed (Fig. 1b, lane 2). As a control, we also incubated $\mathrm{rCdh} 1$ with proteolytic inactive HtrA [36], which does not target E-cadherin (Fig. S1A, compare lanes 1 and 3). The addition of the EDTA and EGTA as calcium-chelating agents (Additional file 1: Figure S1A, lanes 9, 10) strongly increased E-cadherin processing by HtrA, leading to the formation of the $\sim 90 \mathrm{kDa}, \sim 60 \mathrm{kDa}$, and $\sim 50 \mathrm{kDa}$ fragments (Fig. 1b, lane 3). In contrast to this observation, an increase in the calcium ion concentration strongly reduced E-cadherin fragmentation. None of the $100 \mathrm{kDa}, 90 \mathrm{kDa}, 60 \mathrm{kDa}$, or the $50 \mathrm{kDa}$ E-cadherin fragments was detectable anymore. Only a small amount of a $115 \mathrm{kDa}$ truncated E-cadherin could be observed, indicating that calcium ions may block the accessibility of E-cadherin cleavage sites for HtrA (Fig. 1b, lane 4). Unlike $\mathrm{CaCl}_{2}, \mathrm{MgCl}_{2}$ did not influence E-cadherin cleavage (Additional file 1: Figure S1A, lanes 3-5). As further controls, we tested antibodies against E-cadherin (upper panel) or HtrA (lower panel) for possible cross-reactivity against HpHtrA (Fig. 1b, lane 5) or rCdh1 (Fig. 1b, lane 1), respectively. We detected a short HtrA (HpHtrAs) form (Fig. 1b), which has been previously identified by mass-spectrometry analyses as an auto-processed active form of HtrA [36].

\section{Calcium ions do not influence the oligomerization and proteolytic activity of $\mathrm{HpHtrA}$}

To analyze whether calcium affects HtrA activity, increasing concentrations of $\mathrm{CaCl}_{2}$ were incubated with $\mathrm{HtrA}$ and casein in vitro. Casein is composed of $\alpha_{\mathrm{S1}^{-}}$, $\alpha_{\mathrm{S} 2}$-casein and $\beta$-casein (Fig. 2a, lane 1) [37] and serves as an artificial substrate for monitoring the proteolytic activity of HtrA proteases [36]. After incubation of $\mathrm{HpHtrA}$ with casein for $4 \mathrm{~h}$, the proteins were separated by SDS-PAGE and visualized by Coomassie staining (Fig. 2). The results indicate that HpHtrA preferentially cleaved $\alpha_{\mathrm{S1}^{-}}$and $\beta$-casein, which might be explained by the differences between these proteins in relation to hydrophobicity and post-translational modifications [37]. $\alpha_{\mathrm{S} 2}$-Casein was only targeted by HtrA at a low level (Fig. 2a, b, lane 3). Increasing concentrations of calcium ranging from 25 to $400 \mu \mathrm{M}$ did not inhibit HtrA-mediated degradation of $\alpha_{\mathrm{S}}$ - and $\beta$-casein. These observations were further confirmed by the observation that, after $16 \mathrm{~h}$ incubation, $\mathrm{HpH}$ trA-mediated casein degradation was not inhibited by $1 \mathrm{mM} \mathrm{CaCl}$ or $\mathrm{MgCl}_{2}$ (Additional file 1: Figure $\mathrm{S} 1 \mathrm{~B}$ ). In contrast, an obvious decrease in the level of $\alpha_{\mathrm{S} 2}$-casein was detectable in the presence of calcium, indicating a possible increase in HtrA activity and consequently induced casein degradation (Fig. 2a, lanes $4-8$ ). These data were supported by the finding that addition of increasing amounts of EDTA did not alter HtrAmediated $\alpha_{\mathrm{S}^{-}}, \alpha_{\mathrm{S2}^{-}}$and $\beta$-casein cleavage (Fig. 2b). Since the results obtained from these in vitro cleavage assays showed no blocking or enhancement of HtrA activity by calcium after $4 \mathrm{~h}$, we also monitored the kinetics of HtrA-mediated degradation of FITC-labeled casein to finally exclude an inhibitory effect of calcium ions on HtrA activity. As a positive control, increasing concentrations of trypsin were included, which led to a dosedependent increase in the cleavage of the FITC-labeled casein (Fig. 3a). In comparison to $1 \mu \mathrm{g} / \mathrm{ml}$ trypsin, $1 \mu \mathrm{g} /$ 


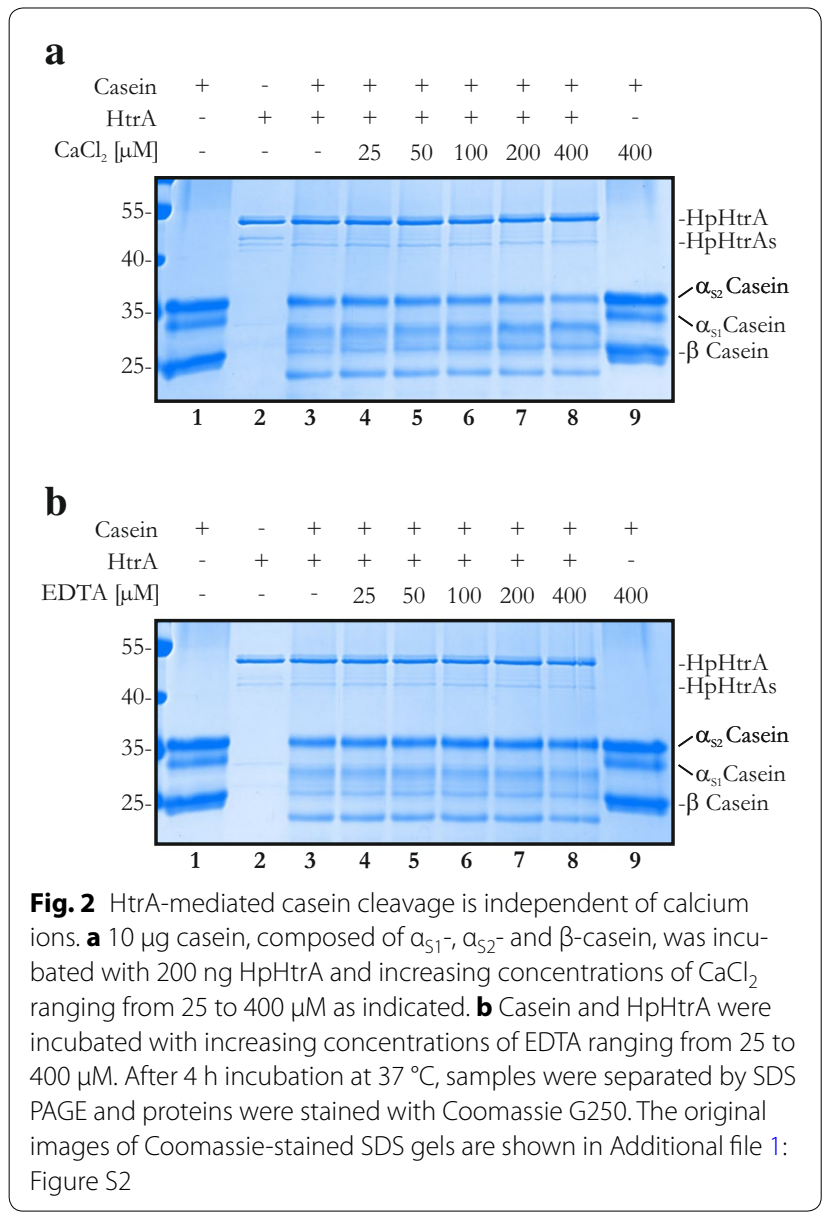

$\mathrm{ml} \mathrm{HpHtrA} \mathrm{was} \mathrm{less} \mathrm{active,} \mathrm{but} \mathrm{induced} \mathrm{an} \mathrm{obvious} \mathrm{casein}$ degradation as reflected by the increase in relative fluorescent units (RFU) (Fig. 3a). Addition of $0.5 \mathrm{mM} \mathrm{CaCl}_{2}$ did not influence the proteolytic activity of HpHtrA during $15 \mathrm{~h}$ of $\mathrm{HpHtrA}$-mediated casein degradation. A similar effect was detected for trypsin (Fig. 3a, c).

$\mathrm{HpHtrA}$ forms proteolytically active oligomeric structures [36]. E. coli DegP has been postulated to convert from an inactive to an active multimer upon substrate binding $[28,29]$. Therefore, we aimed to test whether calcium can affect the oligomerization of HpHtrA. Separating HpHtrA by SDS-PAGE under non-reducing conditions clearly showed HpHtrA as a monomer and two additional multimeric structures (Fig. 4a, lane 1). This is in agreement with our previous studies showing that HpHtrA from worldwide strains can form oligomers [38]. Interestingly, the addition of increasing amounts of $\mathrm{CaCl}_{2}$ did not alter the formation of higher-structured oligomers (Fig. 4a, lanes 2-5). We made similar observations when analyzing the caseinolytic activity of $\mathrm{HpHtrA}$ in zymography experiments (Fig. 4b). The appearance of caseinolytically active $\mathrm{HpHtrA}$ migrating as a monomer and oligomer in the zymogram was independent of $\mathrm{CaCl}_{2}$ (Fig. 4b). These data support the hypothesis that calcium ions do not directly affect the proteolytic activity and oligomerization of $\mathrm{HpHtrA}$.

\section{Calcium ions selectively inhibit HpHtrA-mediated E-cadherin cleavage}

EDTA and calcium did not modify the activity of HtrA, but drastically interfered with E-cadherin cleavage. Therefore, we wanted to titrate the effects of EDTA and calcium on E-cadherin cleavage. Recombinant Cdh1 was incubated with HpHtrA together with increasing concentration of EDTA. At a concentration of $50 \mu \mathrm{M}$ EDTA, a strong increase in E-cadherin fragmentation was observed (Fig. 5a, lane 4), which was further enhanced by increasing the EDTA concentration up to $250 \mu \mathrm{M}$ (Fig. 5a, lanes 5-7). Correspondingly, only low concentrations of calcium ions were necessary to completely block HpHtrA-induced rCdh1 fragmentation. A concentration of $50 \mu \mathrm{M} \mathrm{CaCl}_{2}$ was sufficient to prevent the formation of the $100 \mathrm{kDa}$ fragment (Fig. 5b, lane 4). A further increase in the $\mathrm{CaCl}_{2}$ concentration did not enhance the inhibition of E-cadherin cleavage, which was already limited to the generation of the $115 \mathrm{kDa}$ E-cadherin fragment (Fig. 5b, lanes 5-7).

Calcium plays a crucially important role in the homophilic interactions of the extracellular domains of E-cadherin [5, 7-9]. We hypothesized that the accessibility of E-cadherin cleavage sites for HtrA might be regulated by the presence of calcium ions. To investigate the influence of calcium ions in $H$. pylori-mediated E-cadherin shedding, infected NCI-N87 cells were incubated with increasing concentrations of $\mathrm{CaCl}_{2}$ (Fig. 6a) or EGTA (Fig. 6b). Low concentrations of $\mathrm{CaCl}_{2}$ slightly decreased constitutive E-cadherin shedding through proteases [17], as reflected by the loss of NTF formation in the supernatants and the increase in full-length E-cadherin in whole cell lysates (Fig. 6a, lanes 3-5). However, $1 \mathrm{mM}$ $\mathrm{CaCl}_{2}$ enhanced constitutive cleavage of E-cadherin, most likely through the activation of metalloproteases [39]. Increasing amounts of $\mathrm{CaCl}_{2}$ did not alter $\mathrm{H}$. pyloriinduced NTF formation (Fig. 6a, lanes 7-10) because the cell culture medium already contains $420 \mu \mathrm{M}$ calcium to allow the formation of proper cell-to-cell adhesions via homophilic E-cadherin interactions. Subsequently, cells were treated with increasing concentrations of EGTA, which led to a slight increase in NTF in supernatants of EGTA-treated cells (Fig. 6b). Higher concentrations of EGTA to efficiently complex $\mathrm{Ca}^{++}$in the medium result in dislocation and malfunction of E-cadherin [40] and were not included in this study. In conclusion, our data suggest that binding of calcium ions to E-cadherin masks cleavages sites for HpHtrA in vitro and on epithelial cells, 


\section{a}

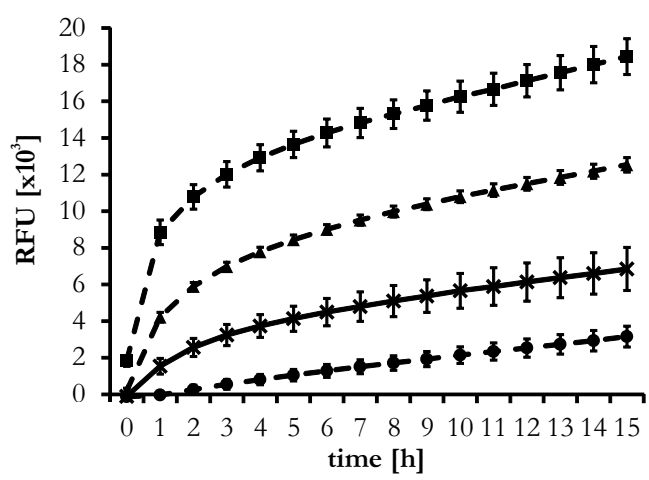

c

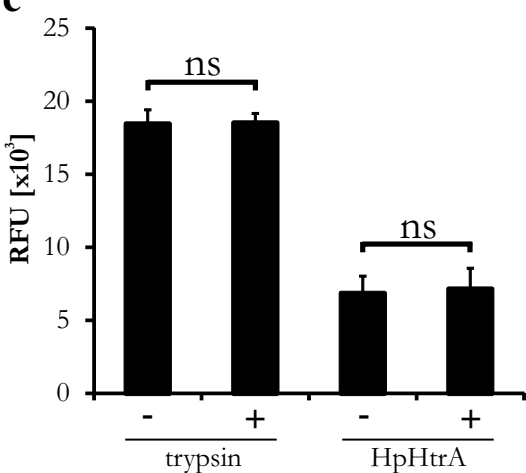

b

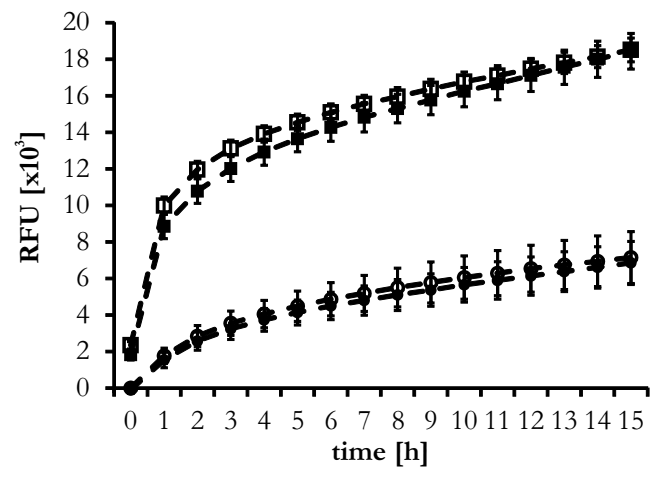

Fig. 3 Calcium ions do not affect HpHtrA activity. a FITC-labeled casein was incubated with $1 \mu \mathrm{g} / \mathrm{ml} \mathrm{HpHtrA} \mathrm{(times)} \mathrm{and} 0.008 \mu \mathrm{g} / \mathrm{ml}$ (filled circle), $0.2 \mathrm{\mu g} / \mathrm{ml}$ (filled triangle), and $1.0 \mathrm{\mu g} / \mathrm{ml}$ (filled square) trypsin as a positive control. b FITC-labeled casein was incubated with $1 \mu \mathrm{gg} / \mathrm{ml}$ trypsin (filled square), $1 \mu \mathrm{g} / \mathrm{ml}$ trypsin $/ 500 \mu \mathrm{M} \mathrm{CaCl}_{2}$ (open square), $1 \mu \mathrm{g} / \mathrm{ml} \mathrm{HpHtrA} \mathrm{(filled} \mathrm{circle),} \mathrm{or} 1 \mu \mathrm{g} / \mathrm{ml} \mathrm{HpHtrA} / 500 \mu \mathrm{M} \mathrm{CaCl}_{2}$ (open circle). Fluorescent signals of the blanks (casein $\pm \mathrm{CaCl}_{2}$ ) were subtracted from the signals of casein with trypsin or HpHtrA. c Direct comparison of relative fluorescent signals of trypsin- or HpHtrA-treated FITC-labeled casein treated with $500 \mu \mathrm{M} \mathrm{CaCl}_{2}(+)$, as indicated, after $15 \mathrm{~h}$. Data from three independent experiments are expressed as relative fluorescent units (RFU) \pm SD

\section{$\mathbf{a}$}

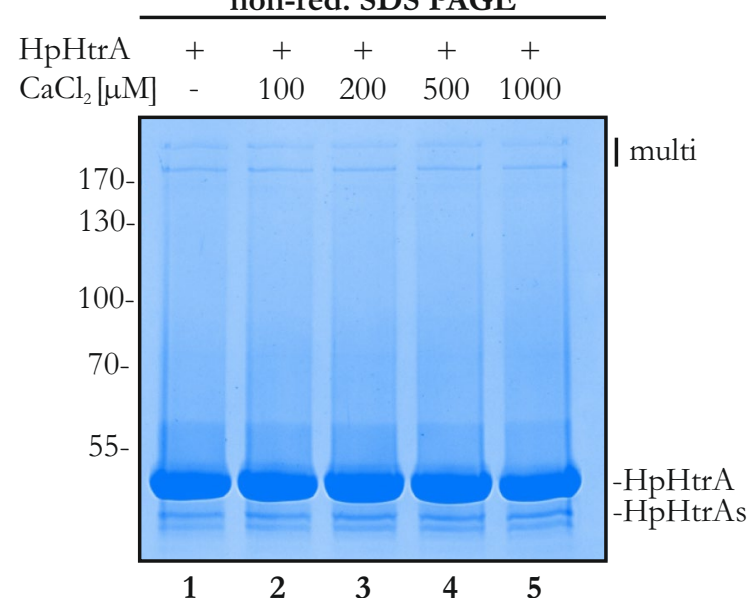

b
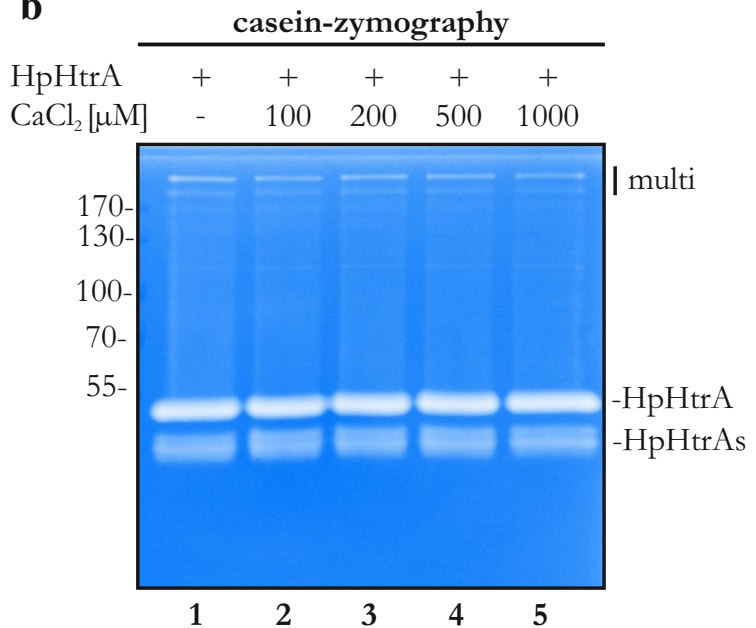

Fig. 4 Calcium does not interfere with oligomerization of HpHtrA. a $3 \mu \mathrm{g} \mathrm{HpHtrA} \mathrm{were} \mathrm{preincubated} \mathrm{with} \mathrm{increasing} \mathrm{concentrations} \mathrm{of} \mathrm{calcium}$ ions, as indicated, followed by separation by SDS-PAGE under non-reducing conditions. Proteins were Coomassie-stained to visualize $\mathrm{HpH} H \mathrm{trA}$ in its monomeric and multimeric (multi) forms. b $200 \mathrm{ng} \mathrm{HpHtrA}$ were incubated with different concentrations of calcium ions for $16 \mathrm{~h}$. Proteolytic activities of HpHtrA and HpHtrAs were analyzed by casein zymography 


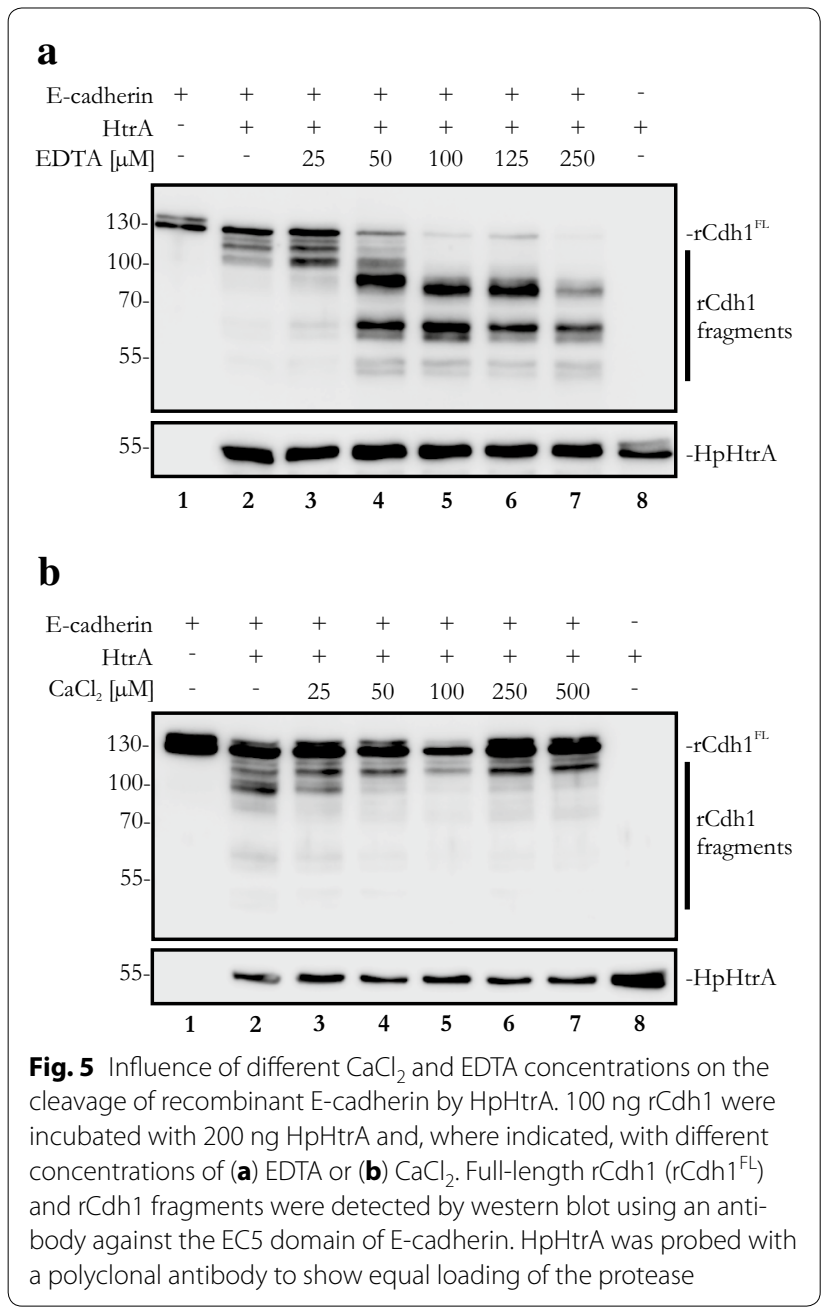

thereby providing a tightly controlled mechanism of E-cadherin shedding.

\section{Discussion}

The controlled cleavage of E-cadherin is a fundamental process in the pathogenesis of $H$. pylori $[20,27,41]$ which could play a crucially important role in gastric carcinogenesis and metastasis. The bacterial serine protease HtrA has been identified as an E-cadherin-targeting protease that directly cleaves off the extracellular domain of E-cadherin to release the soluble $90 \mathrm{kDa}$ NTF into the culture supernatant [27, 33]. Investigations of the different E-cadherin fragmentation patterns upon $H$. pylori infection and in in vitro cleavage experiments have revealed the existence of signature sites for HpHtrA in the E-cadherin molecule (Fig. 7, open arrows) and an additional cleavage site between EC5 and the transmembrane domain (Fig. 7, black arrow). These signature sites are directly targeted in vitro, leading to the formation of a

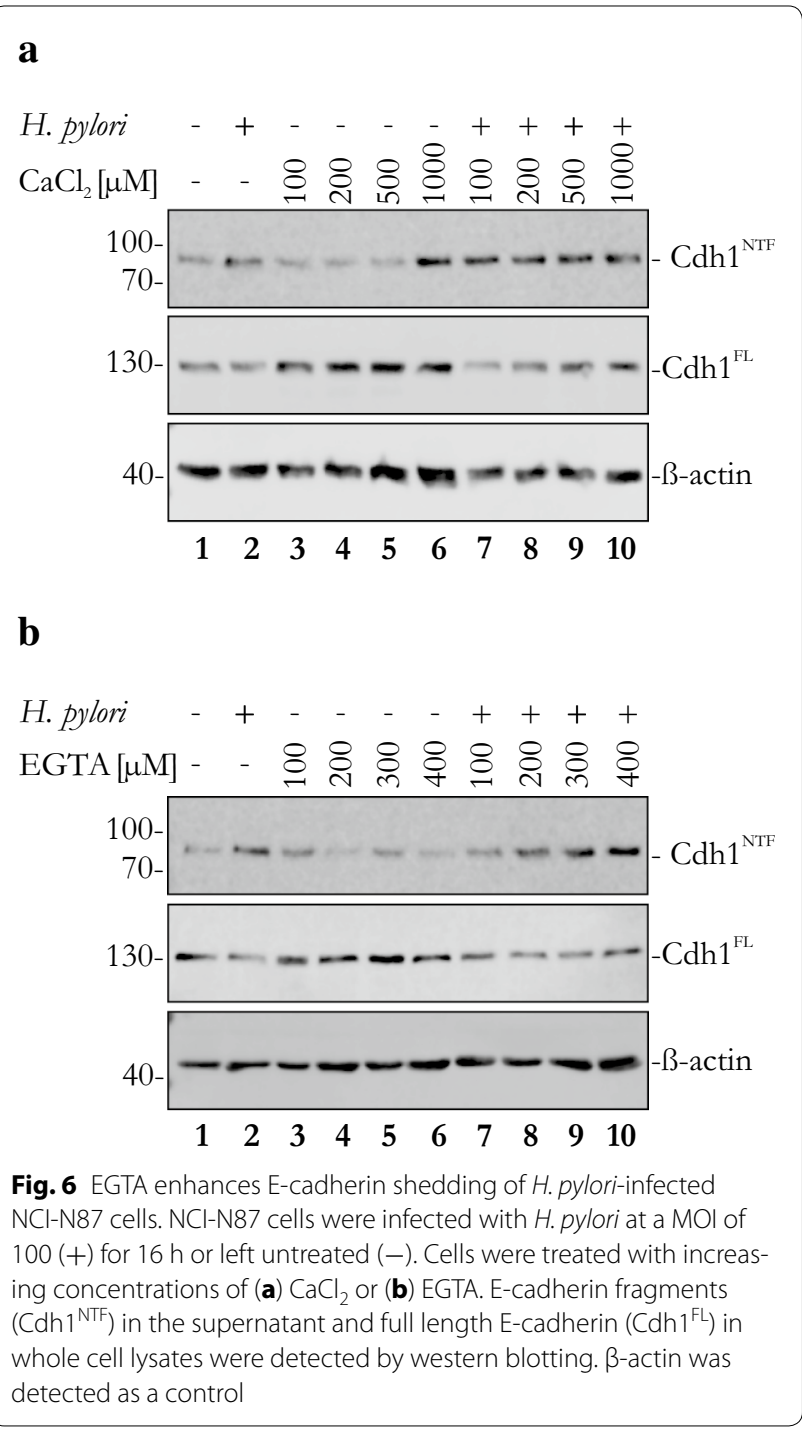

defined fragmentation pattern, which is in contrast to the observed stable $90 \mathrm{kDa}$ EC5-containing NTF detected after infection of gastric epithelial cells [35]. In our current model, the identified HtrA-targeted signature sites are not accessible on epithelial cells through the formation of functional homophilic interactions of the extracellular domain in cis and trans, which might explain the production of the stable $90 \mathrm{kDa}$ NTF upon $H$. pylori infection [35].

Since the HtrA signature sites harbor the binding motifs for calcium, we aimed to investigate whether calcium ions affect the E-cadherin cleavage pattern and found that addition of $\mathrm{Ca}^{2+}$ selectively blocked HtrAmediated E-cadherin cleavage, but did not interfere with the proteolytic activity of HpHtrA per se. The effect of certain divalent cations on proteases of the HtrA family 


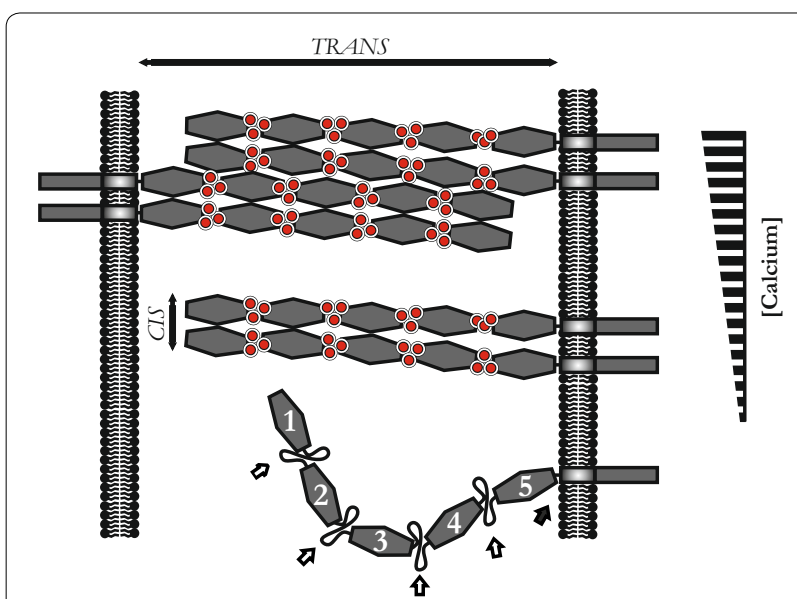

Fig. 7 Model of calcium-regulated HpHtrA-mediated cleavage of E-cadherin. The extracellular N-terminal part of E-cadherin is shown with the identified signature sites (open arrows) between the five EC domains (EC1-EC5) and an additional cleavage site in the linker region (black arrow) for HpHtrA. Signature sites can be bound by calcium ions (red spheres) leading to conformational changes in the E-cadherin molecule, which allow homophilic interactions of E-cadherin in cis and trans. HtrA-mediated E-cadherin cleavage can be inhibited after binding of calcium ions to the signature sites, either by blocking the accessibility of signature sites for HpHtrA or by changing of the conformational structure of E-cadherin

of other species has recently been investigated. It was shown that the activity of Borrelia burgdorferi HtrA (BbHtrA) is inhibited by $\mathrm{Zn}^{2+}, \mathrm{Mn}^{2+}$, and $\mathrm{Cu}^{2+}$, while $\mathrm{Ca}^{2+}$ has no inhibiting activity. Increasing concentrations of $\mathrm{Zn}^{2+}$ also affected the activity of human HtrA1 and E. coli DegP [42], indicating the sensitivity of HtrA proteases towards divalent cations. This shows some disagreement with a previous study, which demonstrates that HpHtrA activity could not be inhibited by high concentrations of bivalent ions (e.g. $\mathrm{Mn}^{2+}, \mathrm{Ca}^{2+}$, or $\mathrm{Mg}^{2+}$ ) [43]. In fact, the activities of HtrA, HhoA (HtrA homologue A), and HhoB (HtrA homologue B) of Synechocystis sp. PCC 6803 increased considerably at high calcium ion concentrations. The authors of this study speculated that bivalent cations might interact with the substrate or that their binding may directly activate the HtrA proteases [44]. Therefore, further studies are necessary to reveal possible differences in the regulation of HtrAs from different species.

From our experiments, we conclude that $\mathrm{Ca}^{2+}$ has the ability to mask the HtrA signature sites by binding to the calcium-binding motifs within the E-cadherin molecule. The calcium-binding motifs are located between the individual EC domains and play important roles in the adhesive function of E-cadherin [7, 45]. E-cadherin depleted of calcium exhibits a bended structure, which might expose the HtrA signature sites (Fig. 7, open arrows).
Binding of calcium to these motifs elongates the curved E-cadherin structure, forming a three-dimensional extracellular structure of adherens junctions through homophilic interactions of the ectodomains in cis and trans (Fig. 7) $[45,46]$. In this complex organized network of E-cadherin molecules, the HtrA cleavage sites are less accessible. This model is supported by our observation that the addition of low calcium ion concentrations efficiently blocked HtrA-mediated E-cadherin cleavage, but did not affect the proteolytic activity of HtrA. Confirming this observation, removal of calcium ions by EDTA considerably increased E-cadherin fragmentation in vitro and on epithelial cells. Although it remains unclear whether inhibition of HtrA-mediated E-cadherin cleavage is a direct consequence of covering the HtrA signature sites for $\mathrm{HpHtrA}$ or due to conformational changes within the E-cadherin proteins, these data suggest that calcium binding to E-cadherin diminishes the accessibility of the signature sites to HtrA. This hypothesis is supported by the observation that calcium chelation by EDTA or EGTA led to a defined cleavage pattern of $\sim 90 \mathrm{kDa}, \sim 60 \mathrm{kDa}$, and $\sim 50 \mathrm{kDa}$ fragments, reflecting the different length of EC5-containing ectodomains of E-cadherin after cleavage of the individual EC tandem repeats starting at the $\mathrm{N}$-terminus (Fig. 7) [35]. Calcium is required in multiple vital cell functions including attachment, morphology, metabolic processes, signaltransduction, replication, etc. [3, 5, 8, 9, 39]. However, whether calcium application relieves $H$. pylori pathogenesis in patients is questionable as $H$. pylori can also activate calcium-dependent E-cadherin-cleaving metalloproteases [27, 41], which can counteract the loss of HtrAmediated E-cadherin cleavage.

In conclusion, calcium-dependent cell adhesions are crucially important for the physiological function of an intact epithelium [12]. HtrA is an essential protein and constitutively expressed and secreted by $H$. pylori [38]. $\mathrm{HpHtrA}$ is certainly important for bacterial physiology, but it has an additional function in infections through its capability of directly cleaving E-cadherin. Since $H$. pylori colonizes the gastric epithelium, we hypothesize that calcium stabilizes E-cadherin junctions and limits HtrAmediated E-cadherin cleavage during infection.

\section{Methods}

\section{Cell culture and infection experiments}

The gastric epithelial NCI-N87 cells (ATCC, CRL-5822) were grown in RPMI 1640 medium containing $4 \mathrm{mM}$ glutamine (Invitrogen) and $10 \%$ FCS (Sigma) in a humidified atmosphere at $37{ }^{\circ} \mathrm{C}$. The $H$. pylori wild-type strain Hp26695 was cultured on agar plates containing $10 \%$ horse serum under microaerophilic conditions for $48 \mathrm{~h}$ at $37^{\circ} \mathrm{C}$ before infection experiments. Cells were infected 
with $H$. pylori at a MOI of 100 for $16 \mathrm{~h}$. To investigate the influence of calcium ions or EGTA on $H$. pylori-mediated E-cadherin cleavage, infections were performed in the presence of indicated concentrations of calcium ions or EGTA. Cells were harvested in lysis buffer $(20 \mathrm{mM}$ Tris $\mathrm{pH}$ 7.5, 1 mM EDTA, $100 \mathrm{mM} \mathrm{NaCl}, 1 \%$ Triton X-100, $0.5 \%$ DOC, $0.1 \%$ SDS, $0.5 \%$ NP- 40 ). Samples were centrifuged for $10 \mathrm{~min}$ at $16,000 \times \mathrm{g}$ at $4{ }^{\circ} \mathrm{C}$ to prepare whole cell lysates. Supernatants of infected cells were collected for the detection of the soluble extracellular E-cadherin fragment.

\section{Recombinant proteins}

Recombinant E-cadherin (Asp155-Ile707, Acc. No. NP_004351) was obtained from R\&D Systems. According to the manufacturer's instructions, lyophilized rCdh1 was reconstituted in Dulbecco's phosphate buffered saline (PBS) containing $\mathrm{MgCl}_{2}$ and $\mathrm{CaCl}_{2}$ (Sigma-Aldrich), resulting in a stock concentration of $100 \mathrm{ng} / \mu \mathrm{lCdh} 1$, $0.9 \mathrm{mM} \mathrm{CaCl}_{2}$, and $0.5 \mathrm{mM} \mathrm{MgCl}_{2}$. Production of recombinant HtrA (HpHtrA, Gly18-Lys475, UniProt G2J5T2) wildtype and the inactive HtrA (Ser221 $\rightarrow$ Ala) from $H$. pylori strain 26,695 has been described elsewhere [36]. Briefly, the GST-tagged HtrA protein was overexpressed in E. coli strain BL21. After lysis and binding of the fusion protein to GSH-Sepharose (GE-Healthcare), the GST-tag was removed by incubation with $180 \mathrm{U}$ PreScission ${ }^{\mathrm{TM}}$ protease (GE-Healthcare). After purification, the protein was dialyzed against $50 \mathrm{mM}$ Tris ( $\mathrm{pH}$ 7.5). Purity of HpHtrA was determined by mass-spectrometry [36] and is routinely analyzed by SDS PAGE ( $92 \%)$. Casein was obtained from Roth (Germany) and reconstituted in $\mathrm{H}_{2} \mathrm{O}$.

\section{In vitro cleavage assays, SDS-PAGE and western blot}

For in vitro cleavage assays, $100 \mathrm{ng}$ rCdh1 was incubated with $200 \mathrm{ng}$ of HpHtrA in $50 \mathrm{mM}$ HEPES, pH 7.5. The reaction volume of $20 \mu \mathrm{l}$ contained a final concentration $45 \mu \mathrm{M} \mathrm{CaCl}_{2}$ and $25 \mu \mathrm{M} \mathrm{MgCl}_{2}$. If not stated otherwise, the in vitro cleavage reaction was incubated at $37{ }^{\circ} \mathrm{C}$ for $16 \mathrm{~h}$. The proteins were separated using SDS-PAGE and blotted onto a nitrocellulose membrane. An antibody recognizing the EC5 domain (Santa Cruz, H108) was used to detect E-cadherin and a polyclonal serum was used to detect HpHtrA as described previously [27]. Alternatively, $10 \mu \mathrm{g}$ of casein (Roth, Germany) was incubated with $200 \mathrm{ng}$ of $\mathrm{HpHtrA}$ at $37^{\circ} \mathrm{C}$ for $4 \mathrm{~h}$ in combination with indicated concentrations of $\mathrm{CaCl}_{2}$, or EGTA. The proteins were separated using SDS-PAGE and visualized using Coomassie G250 (Roth, Germany).

\section{Non-reducing SDS PAGE and casein zymography}

HpHtrA was incubated in $50 \mathrm{mM}$ HEPES ( $\mathrm{pH} 7.5)$ together with increasing concentrations of $\mathrm{CaCl}_{2}$ as indicated. Non-reducing SDS sample buffer without $\beta$-mercaptoethanol was added and samples were separated by SDS PAGE containing $0.1 \%$ casein (Roth). Afterwards, the gel was renatured in $2.5 \%$ Triton-X-100 for $2 \times 30 \mathrm{~min}$ and subsequently equilibrated in developing buffer (50 mM Tris- $\mathrm{HCl}, \mathrm{pH} 7.4,200 \mathrm{mM} \mathrm{NaCl}$, $5 \mathrm{mM} \mathrm{CaCl}_{2}, 0.02 \%$ Brij35) [36] to refold proteins at $37{ }^{\circ} \mathrm{C}$ for $16 \mathrm{~h}$ under gentle agitation. Caseinolytic activity in zymograms was visualized by staining with $0.5 \%$ Coomassie Blue R250. To detect oligomers by SDSPAGE, HtrA was separated as described for zymograms excluding casein as a substrate. All experiments were repeated at least three times.

\section{Protease activity assay using FITC-labeled casein}

Quantification of HpHtrA activity was performed using a fluorescent protease assay kit (Pierce, Thermo Scientific). Trypsin was included as a standard ranging from 0.008 to $1 \mu \mathrm{g} / \mathrm{ml}$ and compared to $1 \mu \mathrm{g} / \mathrm{ml} \mathrm{HpHtrA}$. Where indicated, $0.5 \mathrm{mM} \mathrm{CaCl}{ }_{2}$ was added. The measurements were performed in a white, flat bottom 96-well plate (Nunc) at $37^{\circ} \mathrm{C}$. The fluorescence was measured in a plate reader (Infinite ${ }^{\circledR} 200$ PRO, TECAN) with a filter setting of $485 \mathrm{~nm} / 535 \mathrm{~nm}(\mathrm{Ex} / \mathrm{Em})$. Statistical analysis was performed using the Student's $t$-test (paired, twotailed). Three independent experiments containing three technical replicates were analyzed for every sample. $p$ values $>0.05$ were not considered statistically significant.

\section{Additional file}

Additional file 1. Supplementary information.

\section{Abbreviations}

Cdh1: E-cadherin; EC: extracellular domain; EDTA: ethylenediaminetetraacetic acid; EGTA: ethyleneglycol-bis-tetraacetic acid; Helicobacter pylori: H. pylori; HtrA: high temperature requirement A; IC: intracellular domain; TD: transmembrane domain.

\section{Authors' contributions}

TPS performed the experimental work, drafted and wrote the manuscript. CG and MH contributed to the experimental work. GS participated in the design of the study. SW conceived the study, participated in its design and coordination, and wrote the manuscript. All authors read and approved the final manuscript

\section{Author details}

${ }^{1}$ Cancer Cluster Salzburg, Department of Molecular Biology, Division of Microbiology, Paris-Lodron University, Salzburg, Austria. ${ }^{2}$ Department of Chemistry and Applied Biosciences, Swiss Federal Institute of Technology (ETH), Zurich, Switzerland.

\section{Acknowledgements}

We thank Steffen Backert from the University Nuremberg-Erlangen, Germany for critical discussions and Catherine Haynes for editing the manuscript.

Availability of data and materials

The datasets supporting the conclusions of this article are included within the article and its additional files. 


\section{Competing interests}

The authors declare that they have no competing interests.

\section{Funding}

This work was supported by a Grant from the Austrian science foundation to Silja Wessler (P-24074).

Received: 11 April 2016 Accepted: 30 May 2016

Published online: 06 June 2016

\section{References}

1. Rodriguez-Boulan E, Macara IG. Organization and execution of the epithelial polarity programme. Nat Rev Mol Cell Biol. 2014;15:225-42.

2. Halbleib JM, Nelson WJ. Cadherins in development: cell adhesion, sorting, and tissue morphogenesis. Genes Dev. 2006;20:3199-214.

3. Gumbiner BM. Regulation of cadherin adhesive activity. J Cell Biol. 2000;148:399-404.

4. Boggon TJ, Murray J, Chappuis-Flament S, Wong E, Gumbiner BM, Shapiro L. C-cadherin ectodomain structure and implications for cell adhesion mechanisms. Science. 2002;296:1308-13.

5. Cailliez F, Lavery R. Cadherin mechanics and complexation: the importance of calcium binding. Biophys J. 2005;89:3895-903.

6. Takeda H, Shimoyama Y, Nagafuchi A, Hirohashi S. E-cadherin functions as a cis-dimer at the cell-cell adhesive interface in vivo. Nat Struct Biol. 1999:6:310-2.

7. Pokutta S, Herrenknecht K, Kemler R, Engel J. Conformational changes of the recombinant extracellular domain of E-cadherin upon calcium binding. Eur J Biochem. 1994;223:1019-26.

8. Alattia JR, Ames JB, Porumb T, Tong Kl, Heng YM, Ottensmeyer P, Kay CM, Ikura M. Lateral self-assembly of E-cadherin directed by cooperative calcium binding. FEBS Lett. 1997:417:405-8.

9. Koch AW, Pokutta S, Lustig A, Engel J. Calcium binding and homoassociation of E-cadherin domains. Biochemistry. 1997:36:7697-705.

10. Hyafil F, Babinet C, Jacob F. Cell-cell interactions in early embryogenesis: a molecular approach to the role of calcium. Cell. 1981;26:447-54.

11. Ringwald M, Schuh R, Vestweber D, Eistetter H, Lottspeich F, Engel J, Dolz R, Jahnig F, Epplen J, Mayer S, et al. The structure of cell adhesion molecule uvomorulin. Insights into the molecular mechanism of $\mathrm{Ca}^{2+}$-dependent cell adhesion. EMBO J. 1987;6:3647-53.

12. Niessen CM, Leckband D, Yap AS. Tissue organization by cadherin adhesion molecules: dynamic molecular and cellular mechanisms of morphogenetic regulation. Physiol Rev. 2011;91:691-731.

13. Hazan RB, Kang L, Roe S, Borgen PI, Rimm DL. Vinculin is associated with the E-cadherin adhesion complex. J Biol Chem. 1997:272:32448-53.

14. Maddugoda MP, Crampton MS, Shewan AM, Yap AS. Myosin VI and vinculin cooperate during the morphogenesis of cadherin cell cell contacts in mammalian epithelial cells. J Cell Biol. 2007;178:529-40.

15. Chervin-Petinot A, Courcon M, Almagro S, Nicolas A, Grichine A, Grunwald D, Prandini MH, Huber P, Gulino-Debrac D. Epithelial protein lost in neoplasm (EPLIN) interacts with alpha-catenin and actin filaments in endothelial cells and stabilizes vascular capillary network in vitro. J Biol Chem. 2012;287:7556-72

16. Kikuchi A, Kishida S, Yamamoto H. Regulation of Wnt signaling by proteinprotein interaction and post-translational modifications. Exp Mol Med. 2006:38:1-10

17. Chan AO. E-cadherin in gastric cancer. World J Gastroenterol. 2006:12:199-203.

18. Backert S, Boehm M, Wessler S, Tegtmeyer N. Transmigration route of Campylobacter jejuni across polarized intestinal epithelial cells: paracelIular, transcellular or both? Cell Commun Signal. 2013;11:72.

19. Posselt G, Backert S, Wessler S. The functional interplay of Helicobacter pylori factors with gastric epithelial cells induces a multi-step process in pathogenesis. Cell Commun Signal. 2013;11:77.

20. Weydig C, Starzinski-Powitz A, Carra G, Lower J, Wessler S. CagAindependent disruption of adherence junction complexes involves E-cadherin shedding and implies multiple steps in Helicobacter pylori pathogenicity. Exp Cell Res. 2007;313:3459-71.
21. Murata-Kamiya N, Kurashima Y, Teishikata Y, Yamahashi Y, Saito Y, Higashi H, Aburatani H, Akiyama T, Peek RM Jr, Azuma T, Hatakeyama M. Helicobacter pylori CagA interacts with E-cadherin and deregulates the beta-catenin signal that promotes intestinal transdifferentiation in gastric epithelial cells. Oncogene. 2007;26:4617-26.

22. Oliveira MJ, Costa AM, Costa AC, Ferreira RM, Sampaio P, Machado JC, Seruca R, Mareel M, Figueiredo C. CagA associates with c-Met, E-cadherin, and p120-catenin in a multiproteic complex that suppresses Helicobacter pylori-induced cell-invasive phenotype. J Infect Dis. 2009;200:745-55.

23. Torres J, Perez-Perez G, Goodman KJ, Atherton JC, Gold BD, Harris PR, la Garza AM, Guarner J, Munoz O. A comprehensive review of the natural history of Helicobacter pylori infection in children. Arch Med Res. 2000;31:431-69.

24. Graham DY, Lee SY. How to effectively use bismuth quadruple therapy: the good, the bad, and the ugly. Gastroenterol Clin North Am. 2015:44:537-63.

25. Blaser MJ, Atherton JC. Helicobacter pylori persistence: biology and disease. J Clin Invest. 2004;113:321-33.

26. Peek RM Jr, Crabtree JE. Helicobacter infection and gastric neoplasia. J Pathol. 2006;208:233-48.

27. Hoy B, Lower M, Weydig C, Carra G, Tegtmeyer N, Geppert T, Schroder P, Sewald N, Backert S, Schneider G, Wessler S. Helicobacter pylori HtrA is a new secreted virulence factor that cleaves E-cadherin to disrupt intercellular adhesion. EMBO Rep. 2010;11:798-804.

28. Clausen T, Kaiser M, Huber R, Ehrmann M. HTRA proteases: regulated proteolysis in protein quality control. Nat Rev Mol Cell Biol. 2011;12:152-62.

29. Singh N, Kuppili RR, Bose K. The structural basis of mode of activation and functional diversity: a case study with HtrA family of serine proteases. Arch Biochem Biophys. 2011;516:85-96.

30. Kim S, Sauer RT. Cage assembly of DegP protease is not required for substrate-dependent regulation of proteolytic activity or high-temperature cell survival. Proc Natl Acad Sci USA. 2012;109:7263-8.

31. Boehm M, Hoy B, Rohde M, Tegtmeyer N, Baek KT, Oyarzabal OA, Brondsted L, Wessler S, Backert S. Rapid paracellular transmigration of Campylobacter jejuni across polarized epithelial cells without affecting TER: role of proteolytic-active HtrA cleaving E-cadherin but not fibronectin. Gut Pathog. 2012:4:3.

32. Elmi A, Nasher F, Jagatia H, Gundogdu O, BajajElliott M, Wren BW, Dorrell N. Campylobacter jejuni outer membrane vesicle-associated proteolytic activity promotes bacterial invasion by mediating cleavage of intestinal epithelial cell E-cadherin and occludin. Cell Microbiol. 2016;18:561.

33. Hoy B, Geppert T, Boehm M, Reisen F, Plattner P, Gadermaier G, Sewald N, Ferreira F, Briza P, Schneider G, et al. Distinct roles of secreted HtrA proteases from gram-negative pathogens in cleaving the junctional protein and tumor suppressor E-cadherin. J Biol Chem. 2012;287:10115-20.

34. Boehm M, Lind J, Backert S, Tegtmeyer N. Campylobacter jejuni serine protease HtrA plays an important role in heat tolerance, oxygen resistance, host cell adhesion, invasion, and transmigration. Eur J Microbiol Immuno (Bp). 2015;5:68-80.

35. Schmidt TP, Perna AM, Fugmann T, Bohm M, Jan H, Haller S, Gotz C, Tegtmeyer N, Hoy B, Rau TT, et al. Identification of E-cadherin signature motifs functioning as cleavage sites for Helicobacter pylori HtrA. Sci Rep. 2016;6:23264.

36. Lower M, Weydig C, Metzler D, Reuter A, Starzinski-Powitz A, Wessler $\mathrm{S}$, Schneider $\mathrm{G}$. Prediction of extracellular proteases of the human pathogen Helicobacter pylori reveals proteolytic activity of the Hp1018/19 protein HtrA. PLoS ONE. 2008;3:e3510.

37. Swaisgood HE. Chemistry of the Caseins. In: Fox PF, McSweeney PLH, editors. Advanced dairy chemistry—1 Proteins; 2003. p. 139-201.

38. Tegtmeyer N, Moodley Y, Yamaoka Y, Pernitzsch SR, Schmidt V, Traverso FR, Schmidt TP, Rad R, Yeoh KG, Bow H, et al. Characterisation of worldwide Helicobacter pylori strains reveals genetic conservation and essentiality of serine protease HtrA. Mol Microbiol. 2016;99:925-44.

39. Ito K, Okamoto I, Araki N, Kawano Y, Nakao M, Fujiyama S, Tomita K, Mimori T, Saya H. Calcium influx triggers the sequential proteolysis of extracellular and cytoplasmic domains of E-cadherin, leading to loss of beta-catenin from cell-cell contacts. Oncogene. 1999;18:7080-90.

40. Kowalczyk AP, Nanes BA. Adherens junction turnover: regulating adhesion through cadherin endocytosis, degradation, and recycling. Subcell Biochem. 2012;60:197-222. 
41. Schirrmeister W, Gnad T, Wex T, Higashiyama S, Wolke C, Naumann M, Lendeckel U. Ectodomain shedding of E-cadherin and c-Met is induced by Helicobacter pylori infection. Exp Cell Res. 2009;315:3500-8.

42. Russell TM, Tang X, Goldstein JM, Bagarozzi D, Johnson BJ. The saltsensitive structure and zinc inhibition of Borrelia burgdorferi protease BbHtrA. Mol Microbiol. 2015;99:586.

43. Hoy $B$, Brandstetter $H$, Wessler $\mathrm{S}$. The stability and activity of recombinant Helicobacter pylori HtrA under stress conditions. J Basic Microbiol. 2013;53:402-9.

44. Huesgen PF, Miranda H, Lam X, Perthold M, Schuhmann H, Adamska I, Funk C. Recombinant Deg/HtrA proteases from Synechocystis sp. PCC 6803 differ in substrate specificity, biochemical characteristics and mechanism. Biochem J. 2011;435:733-42.
45. Pertz O, Bozic D, Koch AW, Fauser C, Brancaccio A, Engel J. A new crystal structure, $\mathrm{Ca} 2+$ dependence and mutational analysis reveal molecular details of E-cadherin homoassociation. EMBO J. 1999;18:1738-47.

46. Harrison OJ, Jin X, Hong S, Bahna F, Ahlsen G, Brasch J, Wu Y, Vendome J, Felsovalyi K, Hampton CM, et al. The extracellular architecture of adherens junctions revealed by crystal structures of type I cadherins. Structure. 2011;19:244-56.

\section{Submit your next manuscript to BioMed Central and we will help you at every step:}

- We accept pre-submission inquiries

- Our selector tool helps you to find the most relevant journal

- We provide round the clock customer support

- Convenient online submission

- Thorough peer review

- Inclusion in PubMed and all major indexing services

- Maximum visibility for your research

Submit your manuscript at www.biomedcentral.com/submit 